\title{
NEW QUATERNARY PYRIDINE ALDOXIMES AS CAUSAL ANTIDOTES AGAINST NERVE AGENTS INTOXICATIONS
}

\author{
Kamil Kuča ${ }^{a *}$, Lucie Bartošováa, Daniel Jun ${ }^{\mathrm{a}, \mathrm{b}}$, Jiří Patočka ${ }^{\mathrm{a}, \mathrm{c}}$, Jiří Cabal ${ }^{\mathrm{a}}$, Jiř́i Kassa ${ }^{\mathrm{a}}$, \\ Gabriela Kunešováa
}

\author{
a Department of Toxicology, Faculty of Military Health Sciences, Třebešská 1575, Hradec Králové, Czech Republic \\ b Department of Pharmaceutical Botany and Ecology, Charles University in Prague, Faculty of Pharmacy in Hradec Králové, \\ Hradec Králové, Czech Republic \\ c Department of Radiology and Toxicology, Faculty of Health and Social Studies, South Bohemia University, České \\ Budějovice, Czech Republic \\ e-mail:kucakam@seznam.cz,kucakam@pmfhk.cz
}

Received: May 10, 2005; Accepted: June 7, 2005

Key words: Acetylcholinesterase/Inhibition/Reactivation/HI-6/Pralidoxime/Obidoxime/Reactivator/In vitro

In this work, the ability of four newly synthesized oximes - K005 (1,3-bis(2-hydroxyiminomethylpyridinium) propane dibromide), K027 (1-(4-hydroxyiminomethylpyridinium)-3-(4-carbamoylpyridinium) propane dibromide), K033 (1,4-bis(2-hydroxyiminomethylpyridinium) butane dibromide) and K048 (1-(4-hydroxyiminomethylpyridinium)-4-(4carbamoylpyridinium) butane dibromide) to reactivate acetylcholinesterase (AChE, EC 3.1.1.7) inhibited by nerve agents is summarized. Reactivation potency of these compouds was tested using standard in vitro reactivation test. Tabun, sarin, cyclosarin and VX agent were used as appropriate testing nerve agents. Rat brain AChE was used as a source of the enzyme. Efficacies of new reactivators to reactivate tabun-, sarin-, cyclosarin- and VX-inhibited AChE were compared with the currently used AChE reactivators (pralidoxime, obidoxime and HI-6).

Oxime K048 seems to be promising reactivator of tabun-inhibited AChE. Its reactivation potency is significantly higher than that of HI-6 and pralidoxime and comparable with the potency of obidoxime. The best reactivator of sarin-inhibited AChE seems to be oxime HI-6. None of the new AChE reactivators reached comparable reactivation potency. The same results were obtained for cyclosarin-inhibited AChE. However, oxime K033 is also potent reactivator of AChE inhibited by this nerve agent. In the case of VX inhibition, obidoxime and new oximes K027 and K048 seem to be the best $\mathrm{AChE}$ reactivators.

None from the currently tested AChE reactivators is able to reactivate AChE inhibited by all nerve agents used and, therefore, the search for new potential broad spectrum AChE reactivators is needed.

\section{INTRODUCTION}

Organophosphate (OP) compounds are broadly used in the industry, veterinary and human medicine, in the agriculture or can be misused for military purposes ${ }^{1}$. There are many intoxications due to their broad use over the world ${ }^{2,3}$. Nerve agents such as sarin (GB; O-isopropylmethylfluorophosphonate) soman (GD; O-pinacolylmethylfluorophosphonate), cyclosarin (GF; O-cyclohexylmethylfluorophosphonate), tabun (GA; O-ethyldimethylamidocyanophosphate) and VX agent (O-ethyl-S-(2-diisopropylaminoethyl)-methylthiophosphonate) represent extremely toxic $\mathrm{OPs}^{4}$. The threat of the intoxication with OPs, especially with the nerve agents, is relatively high ${ }^{5,6}$.

OPs inhibit enzyme acetylcholinesterase (AChE, EC 3.1.1.7) via its phosphorylation or phosphonylation at the serine hydroxy group in its active site. Afterwards, AChE is not able to serve its physiological function and intoxicated organism can die due to acute cholinergic crisis?
The current standard treatment for poisoning with highly toxic OPs usually consists of the combined administration of anticholinergic drugs (preferably atropine) and AChE reactivators (called "oximes"). Anticholinergic drugs block effects of accumulated acetylcholine at nicotinic and muscarinic receptor sites, while oximes repair physiological lesions of nerve agents-inhibited AChE by restoring its activity ${ }^{8,9}$.

Pralidoxime (2-PAM; 2-hydroxyiminomethyl-1methylpyridinium chloride), obidoxime (Toxogonin ${ }^{\circledR}$; 1,3-bis(4-hydroxyiminomethylpyridinium)-2-oxa-propane dichloride) and H-oxime HI-6 (1-(2-hydroxyiminomethylpyridinium)-3-(4-carbamoylpyridinium)-2-oxa-propane dichloride) are considered to be the most important AChE reactivators (Fig. 1) ${ }^{10}$. These reactivators are characterised by the presence of several structural features: functional oxime group, quaternary nitrogen group and different length of linking chain between two pyridinium rings in the case of bispyridinium reactivators ${ }^{11-12}$.

Unfortunately, none of the currently used oximes is sufficiently effective against all nerve agents known. They are 
<smiles></smiles>

Pralidoxime<smiles>O/N=C/c1cc[n+](C(Cl)Cl)cc1</smiles>

Obidoxime<smiles>COCn1cccc1C=NO</smiles>

HI-6<smiles></smiles>

K005<smiles>CCC[n+]1ccc(C(N)=O)cc1</smiles>

K027<smiles></smiles>

K033

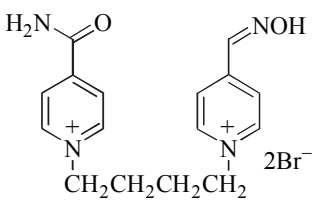

K048

Fig. 1. Structures of currently used oximes and their new analogues.

not able to reactivate nerve agent-inhibited AChE regardless of the type of nerve agent used. While pralidoxime and obidoxime have very low potency to reactivate soman and cyclosarin-inhibited AChE, the oxime HI-6 seems to be practically ineffective to reactivate tabun-inhibited $\mathrm{AChE}^{10,13}$. Therefore, to find another bispyridinium oxime able to sufficiently reactivate nerve agent-inhibited $\mathrm{AChE}$ regardless of the type of nerve agent is still very important task for medicine with the aim to improve the efficacy of antidotal treatment of acute poisonings with nerve agents.

During the last years, four new potential reactivators (K005, K027, K033 and K048) of AChE inhibited by nerve agents were developed at our department (Fig. 1). We tested their ability to reactivate AChE inhibited by nerve agents. Tabun, sarin, cyclosarin and VX were used as typical representatives of nerve agents. All the kinetic measurements were done in vitro using $\mathrm{AChE}$ of the rat brain homogenate as the appropriate source of the enzyme. In this study, there are summarized all our in vitro results obtained within the last years.

\section{MATERIAL AND METHODS}

\section{Chemistry}

The newly synthesized oximes were designated as K005 (1,3-bis(2-hydroxyiminomethylpyridinium) propane dibromide), K027 (1-(4-hydroxyiminomethylpyridinium)3-(4-carbamoylpyridinium) propane dibromide), K033 (1,4-bis(2-hydroxyiminomethylpyridinium) butane dibromide) and K048 (1-(4-hydroxyiminomethylpyridinium)4-(4-carbamoylpyridinium) butane dibromide). Their chemical structures were derived from the structures of currently used AChE reactivators, especially pralidoxime, trimedoxime and HI-6 (Figure 1).

From the chemical point of view, they are bisquaternary symmetric (K005 and K033) or asymmetric (K027 and K048) pyridinium aldoximes with the functional aldoxime group at position two (K005 and K033) or four (K027 and K048) at the pyridine rings. Their synthesis ${ }^{14-16}$ and biological activities ${ }^{17-20}$ were described previously.

\section{Source of the Enzyme}

As a source of AChE, a homogenate of rat brains (Wistar rats individuals weighing 200-240 g without sex preference) was used. The animals were killed in narcosis by cutting carotid arteries, the brains were removed, rinsed in physiological saline and homogenized in an Ultra-Turrax homogenizer (Germany) in distilled water to make a $10 \%$ homogenate.

We have used the rat brain homogenate as a source of the enzyme for three reasons:

(i) The rat brain homogenate has been used in our experiments for many years. Therefore we can compare our new results with the previous ones ${ }^{21-23}$.

(ii) In vitro experiments are followed by in vivo experiments using the experimental animals. To compare our in vitro, and, in vivo results, the same source of AChE should be used ${ }^{24-26}$.

(iii) Data from animal experiments are indispensable for the licensing of oxime by regulatory authorities ${ }^{27}$.

\section{In vitro Experiments}

Standard in vitro method was used for the evaluation of reactivation potencies of mentioned oximes ${ }^{28}$.

Determination of activity of intact $A C h E\left(a_{0}\right)$ : Rat brain homogenate $(0.5 \mathrm{ml})$ was added to a $0.3 \mathrm{M} \mathrm{NaCl}(20 \mathrm{ml})$. 
Then $0.02 \mathrm{M}$ solution of acetylcholine iodide $(2.0 \mathrm{ml})$ was added and the system was adjusted with $0.3 \mathrm{M} \mathrm{NaCl}$ to a total volume of $25.0 \mathrm{ml}$. The liberated acetic acid was titrated with $0.01 \mathrm{M} \mathrm{NaOH}$ on an RTS 822 titrator in the $\mathrm{pH}$-stat mode $(\mathrm{pH} 8.0)$ at room temperature $\left(25^{\circ} \mathrm{C}\right)$. The ionic strength of the solution was rendered with $\mathrm{NaCl}$ at constant value $I=0.25 \mathrm{M}$. The slope of the linear part of the time dependence of the $\mathrm{NaOH}$ used represents the activity of the intact enzyme (in fact, the initial rate of the enzymatic reaction).

Determination of activity of inhibited $A C h E\left(a_{\mathrm{i}}\right)$ : Rat brain homogenate $(0.5 \mathrm{ml})$ was treated with $5.10^{-8} \mathrm{M}$ aqueous solution of nerve agent $(0.5 \mathrm{ml})$ for $30 \mathrm{~min}$, which resulted in about $95 \%$ inhibition of the enzyme. Solution of acetylcholine iodide $(0.02 \mathrm{M}, 2.0 \mathrm{ml})$ was added and the mixture was adjusted to $25.0 \mathrm{ml}$ with $0.3 \mathrm{M}$ $\mathrm{NaCl}$ solution. The activity of the inhibited enzyme $\left(a_{\mathrm{i}}\right)$ was immediately determined analogously as described in the previous experiment.

Determination of activity of reactivated $A C h E\left(a_{\mathrm{r}}\right)$ : Reactivation of the enzyme, inhibited in the above mentioned experiment, was performed immediately after the inhibition. A solution $(1.0 \mathrm{ml})$ of the reactivator was added to the enzyme in appropriate concentration in range $1.10^{-7}-1.10^{-2} \mathrm{M}$. After $10 \mathrm{~min}$ reactivation at $25^{\circ} \mathrm{C}, 0.02 \mathrm{M}$ acetylcholine iodide $(2.0 \mathrm{ml})$ was added. The mixture was adjusted to $25.0 \mathrm{ml}$ with $0.3 \mathrm{M} \mathrm{NaCl}$ solution and immediately afterwards the activity of the reactivated enzyme was determined analogously as described in the previous experiments. According to our observation, the possibility of nerve agent-induced inhibition of released free enzyme during the reactivation of the enzyme is negligible.

Determination of percentage of reactivation $(\% R)$ : The percentage of reactivation $(\% R)$ was calculated from the measured activities of the intact enzyme $a_{0}$, nerve agentinhibited enzyme $a_{\mathrm{i}}$, and reactivated enzyme $a_{\mathrm{r}}$, using equation 1 . The enzyme activity was measured at room temperature $\left(25^{\circ} \mathrm{C}\right)$ and $\mathrm{pH} 8.0$.

$$
\% R=\left[1-\left(a_{0}-a_{\mathrm{r}}\right) /\left(a_{0}-a_{\mathrm{i}}\right)\right] \times 100
$$

Calculation of rate and dissociation constants: The measured values of enzyme activity vs. concentrations of reactivator were used for the calculation of rate and dissociation constants using equation 2 :

$\% A=\left(100 *\left(1-\operatorname{EXP}\left(-t * k_{\mathrm{R}}^{*} C_{\mathrm{R}} /\left(C_{\mathrm{R}}+K_{\mathrm{R}}\right)\right)\right) *\left(1-a_{\mathrm{i}} /\right.\right.$ $\left.\left.a_{0}\right)+100 * a_{\mathrm{i}} / a_{0}\right) /\left(1+\left(C_{\mathrm{S}} / K_{\mathrm{M}}+1\right) * C_{\mathrm{R}} /\left(K_{\mathrm{dis}} * f_{\mathrm{d}}\right)\right)$

where: $\% A=$ percentage of enzyme activity after reactivation, when $100 \%=$ activity of intact enzyme; $t=$ time of the reactivation; $k_{\mathrm{R}}=$ pseudofirst order-rate constant of reactivation for $C_{\mathrm{R}}=\infty ; C_{\mathrm{R}}=$ molar concentration of reactivator; $K_{\mathrm{R}}=$ dissociation constant of the enzyme-inhibitorreactivator complex; $a_{\mathrm{i}}=$ activity of inhibited enzyme; $a_{0}=$ activity of intact enzyme; $C_{\mathrm{s}}=$ molar concentration of substrate; $K_{\mathrm{M}}=$ dissociation constant of enzyme - substrate complex (Michaelis constant); $K_{\mathrm{dis}}=$ dissociation constant of enzyme - reactivator complex; $f_{\mathrm{d}}=$ dilution constant calculated from the ratio of volume of substrate reaction and volume of reactivator reaction; * = multiplication

The first part of the above mentioned equation $\left(1-\operatorname{EXP}\left(-t * k_{\mathrm{R}}{ }^{*} C_{\mathrm{R}} /\left(C_{\mathrm{R}}+K_{\mathrm{R}}\right)\right)\right)$ describes an increase in enzyme activity due to dephosphorylation of the enzyme and the second part $\left(1+\left(C_{\mathrm{S}} / K_{\mathrm{M}}+1\right) * C_{\mathrm{R}} /\left(K_{\mathrm{dis}}{ }^{*} f_{\mathrm{d}}\right)\right)$ describes a decrease in enzyme activity due to a competitive reaction of reactivator and substrate about binding site of enzyme. Fraction $a_{\mathrm{i}} / a_{0}$ introduces correction for subtotal inhibition of enzyme in equation 2. A computer program for non-linear regression was used to calculate reactivation parameters. Calculated parameters were $k_{\mathrm{R}}$, $K_{\mathrm{R}}$ and $K_{\mathrm{dis}}$. Other parameters of equation were introduced as constants.

The second-order rate constant of reactivation $\left(k_{\mathrm{r}}\right)$ was calculated using equation 3 :

$$
k_{\mathrm{r}=} k_{\mathrm{R}} / K_{\mathrm{R}}
$$

Determination of the dissociation constant of enzymereactivator complex: Appropriate volume of $0.01 \mathrm{M}$ solution of the oxime was added to the rat brain homogenate $(0.5 \mathrm{ml})$ so as to achieve the desired oxime concentration $\mathrm{C}_{\mathrm{R}}$ in the interval $5.10^{-5}-5.10^{-2} \mathrm{M}$. Then $0.02 \mathrm{M}$ solution of acetylcholine iodide $(2.0 \mathrm{ml})$ was added, the mixture was adjusted to $25.0 \mathrm{ml}$ with $0.3 \mathrm{M} \mathrm{NaCl}$ and the rate of the enzyme reaction ( $\mathrm{v}$ ) was immediately determined analogously as in the previous experiments. The dissociation constant $\left(\mathrm{K}_{\mathrm{dis}}\right)$ was obtained by non-linear regression from the dependence of $\mathrm{V}$ on $\mathrm{C}_{\mathrm{R}}$ using equation 4 :

$$
v=v_{\max } \times C_{\mathrm{S}} /\left(C_{\mathrm{S}}+K_{\mathrm{M}} \times\left(1+C_{\mathrm{R}} / K_{\mathrm{dis}}\right)\right)
$$

where, in addition to the above-defined symbols, $v_{\max }$ denotes the maximum (limiting) rate of the enzymatic reaction, $C_{\mathrm{S}}$ is the substrate concentration and $K_{\mathrm{M}}$ is the Michaelis constant for hydrolysis of acetylcholine with $\operatorname{AChE}\left(1.9 \times 10^{-4} \mathrm{M}\right)$.

It is generally known that inhibition of $\mathrm{AChE}$ by reactivators has competition character ${ }^{2}$. Dissociation constant $\left(K_{\mathrm{dis}}\right)$ characterizes affinity of ligand (reactivator) to intact enzyme (AChE). Thus, the lower value of $K_{\text {dis }}$ characterizes higher affinity of oxime to AChE. For better predicted antidotal efficacy of oximes, the value of dissociation constant of reactivation $\left(K_{\mathrm{R}}\right)$ should be lower in comparison with the value of $K_{\mathrm{dis}}$.

\section{Statistical evaluation}

Statistical significance was determined by the use of Student's t-test and the differences were considered significant when $P<0.05$. Statistical evaluation was determined with the relevant computer programs ${ }^{29}$. 


\section{RESULTS}

Affinity towards the intact $A C h E$

Values of the constant $K_{\text {dis }}$ characterizing the affinity of newly synthesized oximes to the intact $\mathrm{AChE}$ are shown in Table 1. With a decrease of its value, the affinity of tested oximes to AChE is increasing. As indicated in the Table 1, oxime HI-6 has the lowest value of the constant $K_{\mathrm{dis}}$. His result demonstrates that the affinity of the HI-6 towards the enzyme is the highest among all the tested oximes. Affinity of K033 and K005 oximes is comparable. Oximes K048, pralidoxime and obidoxime exhibit the values of this constant about 10 times higher in comparison with the oxime HI-6. Oxime K027 has the lowest affinity to the intact enzyme among all tested quaternary oximes.

\section{Reactivation of tabun-inhibited AChE}

Kinetic parameters (dissociation constant: $K_{\mathrm{R}}$; rate constants: $k_{\mathrm{R}}$ and $k_{\mathrm{r}}$ ) shown in Table 2 characterize the ability of new oximes to reactivate tabun-inhibited AChE in vitro. The values of the constant $K_{\mathrm{R}}$ characterizing the affinity of oximes to tabun-inhibited AChE indicate that the affinity of obidoxime to the enzyme-inhibitor complex is the highest among all new oximes tested. Values for the oximes K033 and HI-6 are comparable.

The values of the constant $k_{\mathrm{R}}$ express the breakdown of the intermediate complex. The highest value of this constant for oxime K048 was obtained. The values of this constant decrease in the following order: K048 > Obidoxime > K005 > K027 > K033 > HI-6.

Obidoxime has the highest bimolecular constant of reactivation ( $k$, representing overall reactivation ability), followed by K033, HI-6, K048, K027 and K005 (2.4, 5.6, 18, 22.9 and 781 fold lower compared with obidoxime, respectively).

The potency of oximes tested to reactivate tabun-inhibited AChE is demonstrated in Figure 2. In the case of high $\left(10^{-3} \mathrm{M}\right)$ oxime concentration, $28 \%, 16 \%, 15 \%, 2 \%, 1 \%$ and $1 \%$ reactivation of tabun-inhibited $\mathrm{AChE}$ was obtained for K048, K027, K005, HI-6, pralidoxime and K033, respectively. Obidoxime at this concentration was not able to sufficiently reactivate tabun-inhibited AChE. Unfortunately, this concentration is not suitable for humans. In the case of concentration range $\left(10^{-5} \mathrm{M}\right)$ relevant human, the percentage of reactivation of tabun-inhibited AChE does not reach $15 \%$ regardless of the oxime used. The reactivation potency of $\mathrm{K} 048$ at the concentration $10^{-4} \mathrm{M}$ (probably acceptable for human use) is similar to the potency obtained for obidoxime.

According to our evaluation of all kinetic constants and concentration-reactivation relationships of tabun-inhibited $\mathrm{AChE}$, we can confirm that the best reactivator from the new oximes seems to be the K048, however, in the high concentrations only.
Table 1. Affinity of the tested oximes towards acetylcholinesterase.

\begin{tabular}{|c|c|}
\hline Oxime & $K_{\text {dis }}[\mu \mathrm{M}]$ \\
\hline K005 & 53 \\
K027 & 5888 \\
K033 & 65 \\
K048 & 228 \\
Pralidoxime & 210 \\
Obidoxime & 280 \\
HI-6 & 24 \\
\hline
\end{tabular}

Table 2. Kinetic parameters of the reactivation of tabun-inhibited $\mathrm{AChE}$ in rat brain homogenate in vitro.

\begin{tabular}{|c|c|c|c|}
\hline Oxime & $\begin{array}{c}K_{R} \\
{[\mu \mathrm{M}]}\end{array}$ & $\begin{array}{c}k_{R} \\
{\left[\mathrm{~min}^{-1}\right]}\end{array}$ & $\begin{array}{c}k_{r} \\
{\left[\mathrm{M}^{-1} \cdot \mathrm{min}^{-1}\right]}\end{array}$ \\
\hline $\begin{array}{c}\text { Pralidoxime } \\
\text { Obidoxime }\end{array}$ & 575 & 0.006 & 10 \\
HI-6 & 3.2 & 0.020 & 6250 \\
K005 & 2510 & 0.007 & 1111 \\
K027 & 54 & 0.0198 & 8 \\
K033 & 5 & 0.0148 & 273 \\
K048 & 93 & 0.0121 & 2591 \\
\hline
\end{tabular}

Table 3. Kinetic parameters of the reactivation of sarin-inhibited $\mathrm{AChE}$ in rat brain homogenate in vitro.

\begin{tabular}{|c|c|c|c|}
\hline Oxime & $\begin{array}{c}K_{R} \\
{[\mu \mathrm{M}]}\end{array}$ & $\begin{array}{c}k_{R} \\
{\left[\mathrm{~min}^{-1}\right]}\end{array}$ & $\begin{array}{c}k_{r} \\
{\left[\mathrm{M}^{-1} \cdot \mathrm{min}^{-1}\right]}\end{array}$ \\
\hline $\begin{array}{c}\text { 2-PAM } \\
\text { Obidoxime }\end{array}$ & 354 & 0.140 & 403 \\
HI-6 & 9 & 0.380 & 486 \\
K005 & 1940 & 0.210 & 22000 \\
K027 & 281 & 0.083 & 43 \\
K033 & 16 & 0.054 & 191 \\
K048 & 240 & 0.042 & 2695 \\
\hline
\end{tabular}

Table 4. Kinetic parameters of the reactivation of cyclosarin-inhibited $\mathrm{AChE}$ in rat brain homogenate in vitro.

\begin{tabular}{|c|c|c|c|}
\hline Oxime & $\begin{array}{c}K_{R} \\
{[\mu \mathrm{M}]}\end{array}$ & $\begin{array}{c}k_{R} \\
{\left[\mathrm{~min}^{-1}\right]}\end{array}$ & $\begin{array}{c}k_{r} \\
{\left[\mathrm{M}^{-1} \cdot \mathrm{min}^{-1}\right]}\end{array}$ \\
\hline $\begin{array}{c}\text { Pralidoxime } \\
\text { Obidoxime }\end{array}$ & 12000 & 0.040 & 3 \\
HI-6 & - & - & - \\
K005 & 5 & 0.350 & 29000 \\
K027 & - & 0.010 & 2196 \\
K033 & 20 & - & - \\
K048 & - & 0.095 & 4872 \\
\hline
\end{tabular}

$(-)=$ not measurable values 
Table 5. Kinetic parameters of the reactivation of VX-inhibited AChE in rat brain homogenate in vitro.

\begin{tabular}{|c|c|c|c|}
\hline Oxime & $\begin{array}{c}K_{R} \\
{[\mu \mathrm{M}]}\end{array}$ & $\begin{array}{c}k_{R} \\
{\left[\mathrm{~min}^{-1}\right]}\end{array}$ & $\begin{array}{c}k_{r} \\
{\left[\mathrm{M}^{-1} \cdot \mathrm{min}^{-1}\right]}\end{array}$ \\
\hline $\begin{array}{c}\text { 2-PAM } \\
\text { Obidoxime }\end{array}$ & 127 & 0.047 & 370 \\
HI-6 & 562 & 0.330 & 587 \\
K005 & 130 & 0.191 & 1469 \\
K027 & 1350 & 0.132 & 98 \\
K033 & 16 & 0.157 & 867 \\
K048 & 208 & 0.040 & 2469 \\
\hline
\end{tabular}

\section{Reactivation of sarin-inhibited AChE}

The ability of all studied oximes to reactivate sarin-inhibited AChE in vitro is demonstrated in Table 3 (kinetic parameters) and in Figure 3 (relationship concentrationreactivation). The values of the dissociation constant $K_{\mathrm{R}}$ indicate that the affinity of the oxime HI-6 to the enzyme-inhibitor complex is comparable to that of the oxime K033. Their $\mathrm{K}_{\mathrm{R}}$ constants are approximately 20-80 times higher in comparison to other oximes studied. The differences in the affinity of the oxime HI-6 to inhibited enzyme correspond to the differences in the second-order rate constant of sarin-inhibited AChE reactivation $\left(k_{\mathrm{r}}\right)$. According to our results shown in Figure 3, the oxime HI-6 is sufficiently effective to reactivate sarin-inhibited $\mathrm{AChE}$ at the concentrations from $10^{-6}$ to $10^{-4} \mathrm{M}$ that should be attainable for human use. On the other hand, oximes K048, K027, obidoxime and pralidoxime are able to reactivate sufficiently sarin-inhibited AChE in vitro in higher concentration (from $10^{-3}$ to $10^{-2} \mathrm{M}$ only) that would be toxic for human use. In the case of the oxime K033, reactivation potency of this oxime does not reach percentage of the reactivation higher than $30 \%$. Oxime K005 has no potency to reactivate $\mathrm{AChE}$ inhibited by sarin.

\section{Reactivation of cyclosarin-inhibited AChE}

Kinetic parameters shown in Table 4 characterize the ability of the studied oximes to reactivate cyclosarin-inhibited AChE in vitro. We were not able to measure rate constants of the reactivation of cyclosarin-inhibited AChE for obidoxime and new oximes K027 and K048, due to their very low ability to reactivate cyclosarin-inhibited AChE.

The values of the constant $K_{\mathrm{R}}$ characterizing the affinity of oximes to cyclosarin-inhibited $\mathrm{AChE}$ indicate that the affinity of the compound K005 to the enzyme-inhibitor complex is the highest among all new oximes tested. The affinity of other oximes tested decreases as follows: HI-6 > K033 > pralidoxime.

The values of the constant $k_{\mathrm{R}}$ express the breakdown of the intermediate complex. The highest value of this constant for oxime HI-6 was obtained. The values of this constant decrease in the following order: K033 > pralidoxime $>\mathrm{K} 005$.

Oxime HI-6 has the highest bimolecular constant of reactivation $\left(k_{\mathrm{r}}\right)$ representing overall reactivation ability.
Oximes K005 and K033 have comparable values of this constant. The lowest constant was obtained for pralidoxime.

The potency of tested oximes to reactivate cyclosarininhibited $\mathrm{AChE}$ is demonstrated in Figure 4. In the case of oximes HI- 6 and K033, $94 \%$ and $46 \%$ reactivation of cyclosarin-inhibited AChE was obtained at the concentration $10^{-4} \mathrm{M}$. Maximal reactivation potency for pralidoxime $(25 \%)$ was obtained at a very high concentration of the reactivator. Obidoxime, oxime K048 and K005 reached the maximum reactivation potency $13 \%, 11 \%$ and $9 \%$, respectively. Oxime $\mathrm{K} 027$ was not able to reactivate $\mathrm{AChE}$ inhibited by cyclosarin.

According to our evaluation of all kinetic constants and the concentration-reactivation relationship, we can confirm that the best reactivator for cyclosarin-inhibited AChE from the tested oximes seems to be oxime HI-6 followed by the oxime K033, which is the best reactivator of cyclosarin-inhibited AChE from the newly synthesized oximes.

\section{Reactivation of $V X$-inhibited AChE}

The results for VX-inhibited AChE are described in the Table $5 . K_{\mathrm{R}}$, that represents affinity of the quaternary oximes to the inhibited $\mathrm{AChE}$, is the highest for the oxime K005. The values of the $K_{\mathrm{R}}$ for the other oximes are lower. Their values decrease in the following order: obidoxime $>\mathrm{K} 048>\mathrm{K} 027>\mathrm{HI}-6$ > pralidoxime. Oxime K033 is reactivator with the highest affinity towards VX-inhibited AChE among all the oximes tested.

Obidoxime has the highest rate constant $k_{\mathrm{R}}$ for the breakdown of the intermediate complex. The oximes K005, K027, K048 and H-oxime HI-6 have similar values of this constant. The lower value (about 3-times) is demonstrated for pralidoxime and oxime K033.

Oxime K033 has the highest bimolecular constant of reactivation ( $k$, representing overall reactivation ability) than HI-6, K027, K048, obidoxime, pralidoxime and K005 $(1.7,2.8,2.9,4.2,6.7$ and 25.2 fold lower compared to $\mathrm{K} 033$, respectively) due to its low value of the dissociation constant $K_{\mathrm{R}}\left(k_{\mathrm{r}}=k_{\mathrm{R}} / K_{\mathrm{R}}\right)$.

The potency of tested oximes to reactivate VX-inhibited AChE is shown in Figure 5. $10^{-3} \mathrm{M}$ concentration of the obidoxime, oximes $\mathrm{K} 027$ and $\mathrm{K} 048$ is necessary to reach $78 \%, 70 \%$ and $71 \%$ reactivation of VX-inhibited AChE, respectively.

\section{DISCUSSION}

Due to the fact that none of the currently used AChE reactivators is able to reactivate $\mathrm{AChE}$ inhibited by all kinds of nerve agents, search for a new AChE reactivator, which could reactivate AChE inhibited by broad spectrum of nerve agents, is needed. In our work, we have presented reactivation potency of the new bisquaternary pyridinium AChE reactivators - K005, K033, K027 and K048 in tabun-, sarin-, cyclosarin- and VX-inhibited AChE. Although this work presents just in vitro experiments, our 


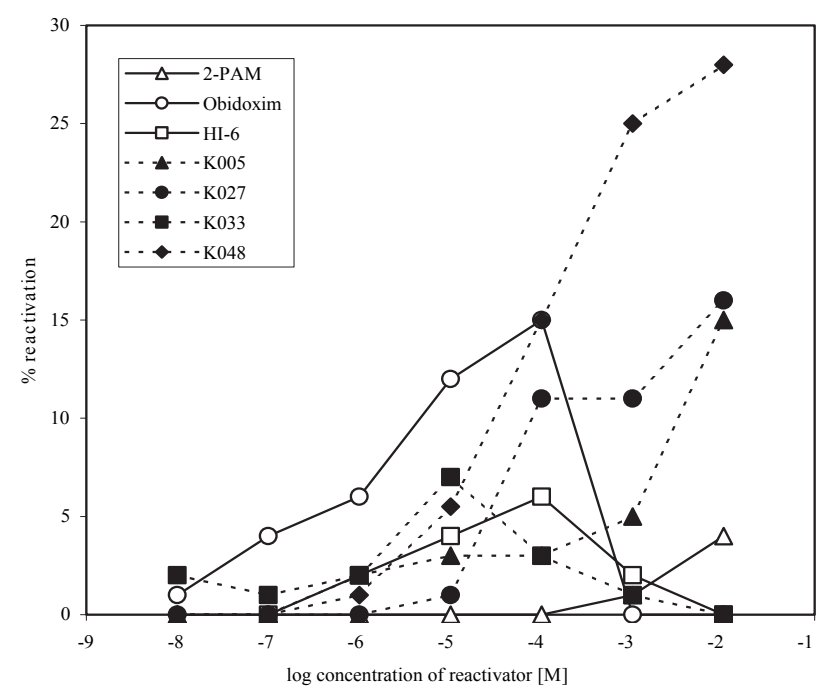

Fig. 2. Reactivation-concentration relationship of oximes to tabun-inhibited AChE

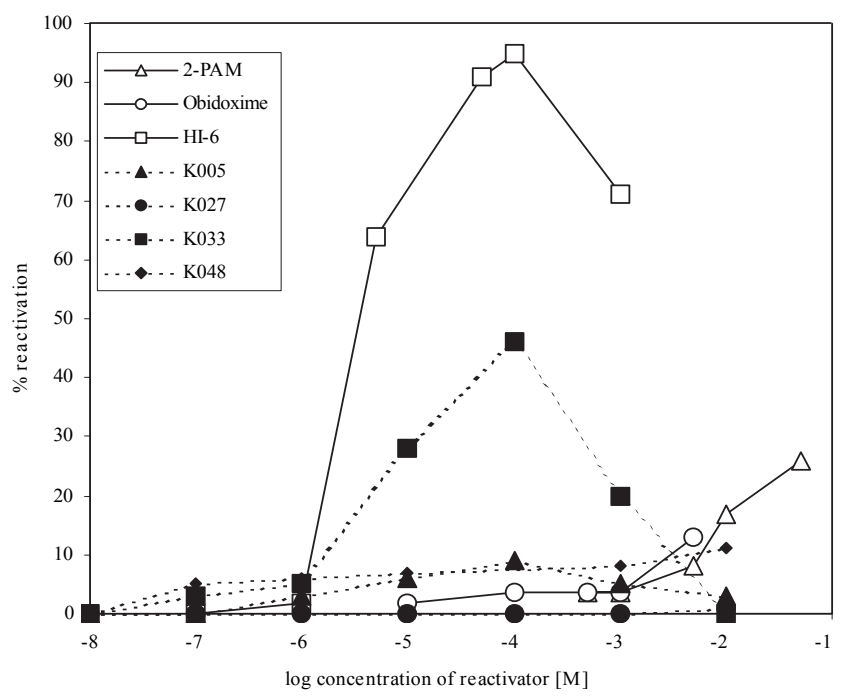

Fig. 4. Reactivation-concentration relationship of oximes to cyclosarin-inhibited $\mathrm{AChE}$

results are important because of the close relationship between in vitro and in vivo results ${ }^{24,25}$.

It is very difficult to find an ideal broad-spectrum reactivator of nerve agents-inhibited AChE. It should have the value of $K_{\mathrm{R}}$ from 10 to 100 times lower than $K_{\mathrm{m}}$ of the native substrate $\left(K_{\mathrm{M}}\right.$ for $\mathrm{AChE}+$ acetylcholine iodide is $200 \mu \mathrm{M}$ ) and the value of $K_{\text {dis }}$ from 10 to 100 times higher than $K_{\mathrm{M}}{ }^{18}$. Thus, the affinity of the AChE reactivator to the inhibited enzyme should be higher than the affinity to the reactivated or, intact enzyme. Ratio between these both constants $\left(K_{\text {dis }}\right.$ and $\left.K_{\mathrm{R}}\right)$ differ according to the nerve agent used ${ }^{24,25}$.

Our results presented in this work confirm the fact that the reactivation of inhibited AChE depends not only on the inhibitor used but also on the chemical structure of the reactivator ${ }^{11,12,14}$. Reactivators differ from each other by the position of the oxime group on the pyridinium ring

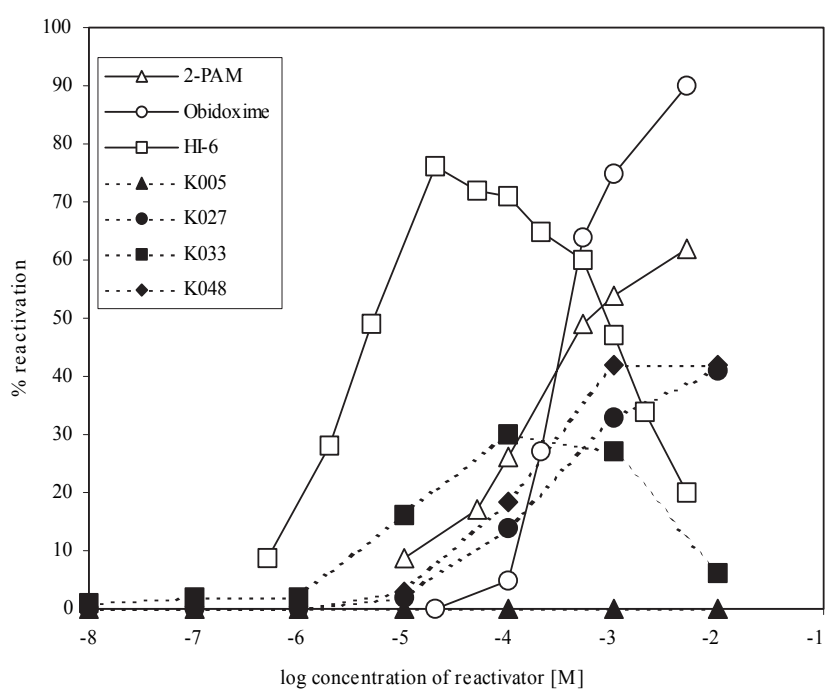

Fig. 3. Reactivation-concentration relationship of oximes to sarin-inhibited $\mathrm{AChE}$

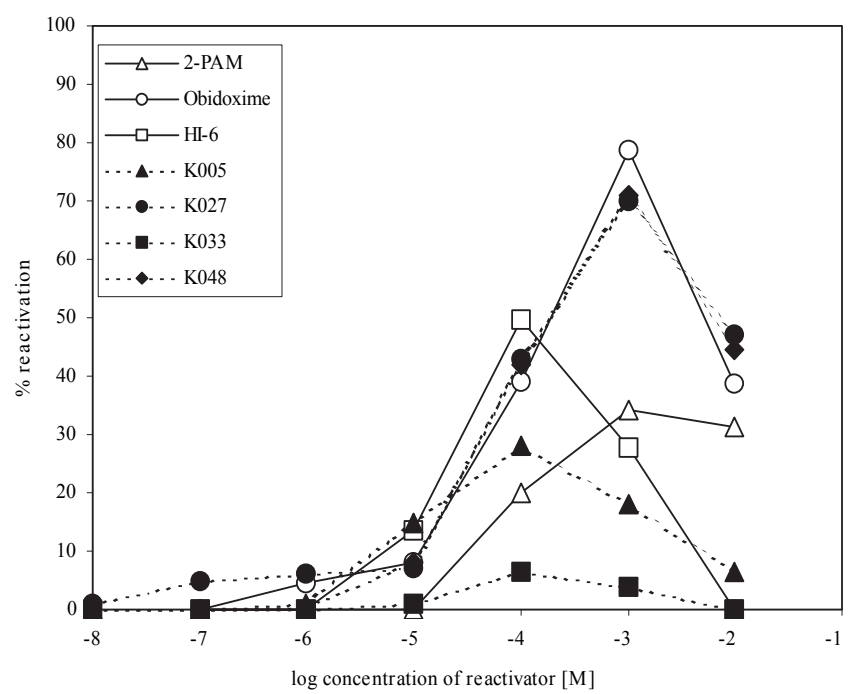

Fig. 5. Reactivation-concentration relationship of oximes to VX-inhibited AChE

and, in the case of bispyridinium oximes, by the chemical structure of the bridge between both pyridinium rings only ${ }^{11}$

Oxime K005 does not reactivate sarin inhibited AChE in vitro. On the other hand, it is able to reactivate cyclosarin and VX-inhibited AChE. However, its reactivation potency in both cases is lower than that for all currently used oximes (pralidoxime, obidoxime and HI-6). In the case of tabun intoxications, its reactivation is lower compared to HI-6 and comparable with pralidoxime and obidoxime at the high concentrations of the oximes ${ }^{16,19,30}$.

Oxime K027 seems to be a good reactivator of organophosphates-inhibited AChE. Its reactivation potency is lower compared to the other oximes in the case of the reactivation of sarin-inhibited $\mathrm{AChE}$, nevertheless, it is sufficient to significantly increase the activity of sarin-inhibited AChE. On the other hand, its reactivation ability 
is comparable to obidoxime in the case of reactivation of VX- and tabun-inhibited AChE. In addition, its reactivation potency of tabun-inhibited $\mathrm{AChE}$ is higher than that of the oxime HI-6, which is currently regarded to be the most promising reactivator of organophosphates-inhibited $\mathrm{AChE}^{14,19}$.

Oxime K033 was found to be more efficacious reactivator of sarin and cyclosarin-inhibited AChE than pralidoxime and obidoxime but it did not reach the efficacy of the oxime HI-6 in the case of the inhibition of AChE by sarin or cyclosarin. On the other hand, the oxime K033 is more efficacious than the oxime HI-6 to reactivate tabun-inhibited $\mathrm{AChE}^{16,20,30}$.

Oxime K048 was found to be more efficacious reactivator of nerve agents-inhibited AChE than pralidoxime (in the case of VX, tabun and cyclosarin), obidoxime (in the case of cyclosarin and tabun) and HI-6 (in the case of tabun) but it did not reach the efficacy of currently used oximes in the case of the inhibition of AChE by $\operatorname{sarin}^{15,17}$

None of the newly synthesized AChE reactivators is able to reactivate $\mathrm{AChE}$ inhibited by all tested nerve agents. Comparison of the currently used oximes (pralidoxime, obidoxime and HI-6) with our newly synthesized oximes (K005, K027, K033 and K048) confirms that there is no single $\mathrm{AChE}$ reactivator, which can universally reactivate $\mathrm{AChE}$ inhibited by all nerve agents.

\section{CONCLUSION}

We have synthesized and tested in vitro four new AChE reactivators (K005, K033, K027 and K048). Their reactivation potency was studied using tabun-, sarin-, cyclosarin-and VX-inhibited AChE. Although none of the new $\mathrm{AChE}$ reactivators was able to reactivate $\mathrm{AChE}$ inhibited by all nerve agents tested, their abilities to reactivate nerve agents inhibited $\mathrm{AChE}$ in vivo using standard reactivation tests will be soon tested ${ }^{31-33}$.

\section{ACKNOWLEDGEMENT}

The authors are grateful to Mrs. I. Ježková and Mrs. M. Hrabinová for their skilful technical assistance. This work was supported by the grants of Ministry of Defense No. OBVLAJEP20032 and ONVLAJEP20031.

\section{REFERENCES}

1. Bajgar J. (1992) Biological monitoring of exposure to nerve agents Brit J Ind Med 49, 648-53.

2. Bajgar J. (2004) Organophosphates/nerve agents poisoning: mechanism of action, diagnosis, prophylaxis and treatment. Adv Clin Chem 38, 151-216.

3. Bajgar J. (1998) Cholinesterases and their possible influencing. Voj Zdrav Listy 67, 1-6.

4. Zajtchuk R, Bellamy RF. Medical aspects of chemical and biological warfare. Office of the Surgeon General: Department of the Army, United states of America, 1997.
5. Yokoyama K, Araki S, Murata K, Nishikitami M, Okomura T, Ishimatsu S, Takasu M. (1998) Chronic neurobehavioral and central autonomic nervous system effects in Tokyo subway sarin poisoning. J Physiol 92, 317-23.

6. Tucker JB. Evidence Iraq used chemical waepons during the 1991 Persian Gulf War. The Nonproliferation Review: Spring-Summer 1997, pp 114-122.

7. Marrs TC. (1993) Organophosphate poisoning. Pharmacol Therap 58, 51-66.

8. Taylor P. Anticholinergic agents. The Pharmacological Basis of Therapeutics. McGraw Hill: New York, 1996.

9. Bajgar J. (1994) The influence of inhibitors and other factors on cholinesterases. Sb Ved Praci LFUK (Hradec Kralove) 34, 3-77.

10. Kassa J. (2002) Review of oximes in the antidotal treatment of poisoning by organophosphorus nerve agents. J Toxicol Clin Toxicol 40, 803-16.

11. Kuča K, Patočka J, Cabal J. (2003) Reactivation of organophosphate inhibited acetylcholinesterase activity by $\alpha, \omega$-bis-(4-hydroxy iminomethylpyridinium)alkanes in vitro. J Appl Biomed 1, 207 11.

12. Bielavský J, Kassa J, Elsnerová I, Dejmek L. (1997) Cholinesterase reactivators derived from pyridine-2-carbaldoxime, Collect Czech Chem Commun 63, 199-204.

13. Cabal J, Bajgar J. (1999) Tabun - Reappearance 50 years later Chemicke Listy 93, 27-9. (in Czech)

14. Kuča K, Bielavský J, Cabal J, Bielavska M. Synthesis of a potential reactivator of acetylcholinesterase-1-(4-hydroxyiminomethylpyridinium)-3-(carbamoylpyridinium) -propane dibromide. (2003) Tetrahedron Lett 44, 3123-25.

15. Kuča K, Bielavský J, Cabal J, Kassa J. (2003) Synthesis of a new reactivator of tabun-inhibited acetylcholinesterase. Bioorg Med Chem Lett 13, 3545-7.

16. Kuča K, Cabal J, Patočka J, Kassa J. (2004) Synthesis of bisquaternary symmetric $-\chi, \delta$-bis (2-hydroxyiminomethylpyridinium)alkane dibromides and their reactivation of cyclosarin-inhibited acetylcholinesterase. Lett Org Chem 1, 84-6.

17. Kuča K, Kassa J. (2003) A comparison of the ability of a new byispyridinium oxime-1-(4-hydroxyiminomethylpyridinium)-4-(4carbamoylpyridinium)butane dibromide and currently used oximes to reactivate nerve agent-inhibited rat brain acetylcholinesterase by in vitro methods. J Enzyme Inhib Med Chem 18, 529-35.

18. Kuča K, Kassa J. (2004) In vitro reactivation of acetylcholinesterase using the oxime K027. Vet Hum Toxicol 46, 15-8.

19. Kuča K, Dohnal V. (2004) 1,3-bis(2-hydroxyiminomethylpyridinium) propane as the potential reactivator of the acetylcholinesterase inhibited by nerve agents. Acta Medica (Hradec Kralove) 47, 167-9.

20. Kuča K, Cabal J, Kassa J. (2004) A comparison of the efficacy of a bispyridinium oxime-1,4-bis-(2-hydroxyiminomethylpyridinium) butane dibromide and currently used oximes to reactivate sarin, tabun or cyclosarin-inhibited acetylcholinesterase by in vitro methods. Pharmazie 59, 795-8.

21. Patočka J, Bielavský J, Ornst F. (1970) Reactivating effect of alpha,omega-bis-(4-pyridinealdoxime)-2-trans-butene dibromide on isopropyl-methylphosphonylated acetylcholinesterase. FEBS Lett 10, 182-4.

22. Patočka J, Bielavský J. (1972) Affinity of bis-quaternary pyridinealdoximes for the active centre of intact and isopropylmethylphosphonylated acetylcholinesterase. Coll Czech Chem Commun 37, 2110-6.

23. Kuča K, Patočka J. (2004) Reactivation of cyclosarin-inhibited rat brain acetylcholinesterase by pyridinium-oximes. J Enzyme Inhib Med Chem 19, 39-43.

24. Kassa J, Cabal J. (1999) A comparison of the efficacy of acetylcholinesterase reactivators against cyclohexyl methylphosphonofluoridate (GF agent) by in vitro and in vivo methods. Pharmacol Toxicol 84, 41-5.

25. Kassa J, Cabal J. (1999) A comparison of the efficacy of a new asymmetric bispyridinium oxime BI-6 with presently used oximes and $\mathrm{H}$ oximes against sarin by in vitro and in vivo methods. Hum Exp Toxicol 18, 560-5. 
26. Kassa J, Cabal J. (1999) A comparison of the efficacy of a new asymmetric bispyridinium oxime BI-6 with currently available oximes and $\mathrm{H}$ oximes against soman by in vitro and in vivo methods. Toxicology 132, 111-8.

27. Worek F, Reiter G, Eyer P, Szinicz L. (2002) Reactivation kinetics of acetylcholinesterase from different species inhibited by highly toxic organophosphates. Arch Toxicol 76, 523-9.

28. Kuča K, Pícha J, Cabal J, Liška F. (2004) Synthesis of the three monopyridinium oximes and evaluation of their potency to reactivate acetylcholinesterase inhibited by nerve agents. J Appl Biomed 2, 51-6.

29. Tallarida R, Murray R. Manual of Pharmacological Calculation with Computer Programs. Springer-Verlag: New York 1987.
30. Kuča K, Cabal J. (2003) An in vitro comparison of the reactivator efficacy of potential symmetric bisquaternary acetylcholinesterase reactivators which differ in their connecting chain length. Voj Zdrav Listy 72, 129-31 (in Czech).

31. Ševelová L, Vachek J. (2003) Effect of methoxime combined with anticholinergic, anticonvulsant or anti-HCN drugs in tabun-poisoned mice. Acta Medica (Hradec Kralove) 46, 109-12.

32. Ševelová L, Kuča K, Krejčová-Kunešová G. (2004) Antidotal treatment of GF-agent intoxication in mice with bispyridinium oximes. Toxicology 207, 1-6.

33. Ševelová L, Kuča K, Krejčová G, Vachek J. (2004) Therapeutic efficacy of oxime treatment in cyclosarin-poisoned mice pretreated with combination of pyridostigmine, benactyzine and trihexyphenidyl. J Appl Biomed 2, 163-7. 